\title{
AUTORIDADES, FORÇAS E VIOLÊNCIAS em “CASAs de ferro”, de Jỗo Paulo Borges CoElHo: entre A ABERTURA ho DESCONHECIDO E A IMAGINAÇÃO DO FUTURO
}

\author{
Rui Gonçalves Miranda'
}

\begin{abstract}
Resumo: “Casas de ferro", de João Paulo Borges Coelho, nomeadamente a abordagem da estória aos indícios do mar Índico, funciona como um ponto de partida para uma reflexão sobre questões de lei, autoridade, força e violência. A estória suplementa literariamente visões históricas, geográficas, políticas e filosóficas; o mar, enquanto dispositivo textual e literário, irrompe no final da estória como elemento de conflito e suspensão, deixando o final em aberto e colocando em cena uma abertura ao desconhecido que permite repensar as relações entre o próprio e o outro enquanto mais que simplesmente o outro do próprio; entre os outros que os próprios (Autoridade e Força) procuram apropriar e espoliados (moradores e refugiados) em nome de uma lei e de um discurso que, extravasando o colonialismo (bem como o neocolonialismo e a pós-colonialidade), cinicamente apelam ao bem comum e simulam ter em mente os interesses da população e do "desenvolvimento" do país. O mar Índico, topos e tropo, não configura simplesmente um outro espaço/lugar (sob trajes utópicos e/ou heterotópicos) ou um outro "Futuro" que contrabalance o que se passa em terra firme, projetado pela Autoridade e respetiva Força. O mar (e os elementos associados, como os barcos e o areal) funciona como um dispositivo que ativa o papel e o direito da literatura de abordar o "real acontecido", ao mesmo tempo que "imagina o futuro" e sugere visões alternativas às dominantes.
\end{abstract}

Palavras-chave: mar Índico; Achille Mbembe; Jacques Derrida.

\section{TEXTOS E CONTEXTOS}

As estórias de João Paulo Borges Coelho nos volumes Índicos indícios I: Setentrião (2005) e Índicos indícios II: Meridião levam a cabo

1 Associate Professor, Universidade de Nottingham Reino Unido: rui.miranda@ nottingham.ac.uk. O autor gostaria de agradecer o apoio da Fundação Ciência e Tecnologia (SFRH/BPD/71245/2010) na elaboração de pesquisa que contribuiu para este artigo. 
um mapeamento das porosas fronteiras, culturalmente falando, de uma secção da África Oriental, a costa de Moçambique. É uma localização relativamente marginal à conceptualização e estudos do Oceano Índico e, sobretudo, marginalizada, como aponta Michael Pearson, utilizando o termo "Afrasian sea" [mar Afrasiático] (1998) para colocar em relevo a contribuição histórica, cultural e comercial dos povos e civilizações da costa Este Africana e do interior do continente a ela associado. As estórias são um contributo para uma abordagem ao Oceano Índico enquanto método (HOFMEYR, 2014), especificamente em relação aos traços (no sentido derridiano do termo) de um mar que simultaneamente reforçam e colocam em xeque uma ideia substantiva de "comunidade nacional". A insubstancialidade de base do construto de nacionalidade, revelada nas estórias pelos traços do mar e pelo mar como um traço, sugere uma suplementação do conceito de "dissemiNation" de Homir Bhabha (1990) por algo como diseamination. O “mar Índico molha”, como aponta Borges Coelho na introdução ao primeiro volume de estórias, toda a extensão da longa costa moçambicana, envolvendo igualmente as "inúmeras" ilhas (COELHO, 2005, p. 9). O mar Índico é muito mais que um limite: a costa moçambicana e a água do mar Índico formam vasos comunicantes que, histórica e estoricamente, se alimentam mutuamente:

Uma água mansa que também sabe enfurecer-se. Azul, se lhe bate o sol, mas tantas vezes parda, tingida por tudo o que essa costa deixa que se escape pelas suas líquidas veias - terras e ramagens, memórias e afogados, enredos e procuras - que ali se abrem para a fertilizar. (COELHO, 2005, p. 9)

O recurso ao mar Índico enquanto método histórico-político dispositivo literário permitirá recuperar $e$ recriar não só um espaço, mas contextos e textos ("memórias e afogados, enredos e procuras"). Não sendo um mero limite, muito menos é um simples ponto de fuga em direção ao outro ou a um espaço outro.

O vaivém das marés reenvia, em primeiro lugar, para a alteridade na própria comunidade nacional, como o demonstra a estória "Casas de ferro", sob análise neste artigo, em que uma comunidade de residentes é expulsa e perseguida pelas (devidamente capitalizadas, no texto) Autoridades e Força Municipal (testas-de-ferro, em grande parte, de Empresários e interesses capitalistas). A par de outras estórias no volume, "Casas de ferro" aborda as problemáticas e os desafios a enfrentar pelas comunidades e, neste caso em particular, pela comunidade pós-colonial moçambicana. A inflexão em torno da especificidade de diferentes comunidades costeiras 
funciona inseparavelmente como um ponto de partida para considerações gerais sobre reinvindicações sociopolíticas, democracia e direitos humanos e demais desafios a enfrentar durante o processo de democratização, pósindependência e pós-guerra civil. Sem esquecer, claro está, os desafios levantados por remanescências coloniais (a começar pelo Grande Hotel) e forças colonialistas internas e neocoloniais - com corpo visível (como a Força Municipal) ou não (como os Empresários, que se manifestam fisicamente pelos seus avatars, os camartelos e maquinaria de demolição).

Em segundo lugar, a estória reenvia os residentes do Grande Hotel, uma vez expulsos, para os barcos encalhados no areal. A evocação do espaço e de estruturas metonimicamente associadas com o processo histórico do colonialismo não esgota o sentido desse limiar alheio à apropriação, ocupação ou ordenação (físicas e/ou simbólicas). "Casas de ferro" termina precisamente na margem, com a subida das águas do mar, que resgatam os emigrados ex-moradores do Grande Hotel da Beira da perseguição pelas forças e leis das "Autoridades" subjugadas a ditames economicistas e movidas por interesses obscuros (empreendimentos turísticos e/ou construção). Elena Brugioni (2012, pp. 389-390) ressalta a contribuição de Borges Coelho para a reformulação e questionamento de um espaço-tempo batizado pelas "fronteiras do espaço nacional". Aponta ainda, na escrita de Borges Coelho, para a "problematização da relação entre história e contemporaneidade e o contraponto entre memórias e representações", sublinhando a forma como "convoca tempos e espaços inéditos e problematizantes, proporcionando uma reflexão situada em torno dos lugares e dos momentos cruciais da contemporaneidade pós-colonial" (COELHO, 2010, p. 428). A sua escrita coloca em questão (e como questão) a lógica e a legitimidade subjacentes às fronteiras (nacionais e linguísticas) e discursos (ideológicos e [a]políticos):

\footnotetext{
Não diria que tenho a intenção de fazer uma cartografia sistemática do país, embora os Î́ndicos indícios possam levar a tal ideia. O espaço nacional tem uma importância relativa na medida em que eu podia ter incluído narrações suscitadas por Bagamoyo (na Tanzania) ou Swakopmund (na Namíbia), por exemplo. O fio que unia estas contas era o mar, e sinto que tenho ainda para explorar o enigma da relação conflituosa que África tem com o mar (será por este ter tragado sucessivas ondas de escravos?). (COELHO, 2009, p. 155)
}

Borges Coelho destaca claramente o papel fulcral do mar Índico para a articulação, sem compromisso, dos pilares geográficos e históricos das estórias. Como refere o autor, em entrevista a Rita Chaves: 
No meu projecto literário (ou melhor, no conjunto aberto daquilo que escrevi e que o balanço entre acaso e intenção me levar a escrever no futuro), esta geografia ampla e misteriosa é um pilar não menos importante do que a história. A bem dizer, trata--se menos de uma geografia no sentido clássico, de leitura e domesticação do espaço, e mais de uma intuição geográfica como forma de abertura ao desconhecido a que se chega por meio da viagem. (COELHO, 2009, p. 156)

Este artigo propõe que não se tome de ânimo leve a proposta de "abertura ao desconhecido" que Índicos indícios, em geral, e "Casas de ferro", em particular, desenvolvem. Em assumida divergência com os estereótipos imputados às literaturas africanas homoglotas e contornando a moçambicanidade - Brugioni fala, em entrevista a Borges Coelho (2010, p. 428), numa "ressemantização do espaço literário nacional moçambicano" -, bem como o paradigma do escritor enquanto "voz colectiva” engajada com a nação (p. 438). No limite, nas palavras de Borges Coelho, a "literatura não pretende transformar o mundo, apenas propor visões alternativas” (COELHO, 2010, p. 429). Crucialmente, acrescenta, na mesma entrevista, que a "exploração de visões alternativas não significa descomprometimento social” (p. 430). O imbricamento proposto pelo autor (comprometimento social da literatura enquanto literatura) serve de aviso contra redutoras leituras miméticas; e é um ponto a ter em conta, dada a tendência de certa crítica literária em tratar textos das literaturas africanas homoglotas como "documento" (antropológico, histórico, social etc.), sendo ainda objeto de forte exoticização (cf. COELHO, 2010, p. 439; e COELHO, 2011, p. 108). É nesse contexto que a observação, pela parte de Borges Coelho, de que "o escritor americano é um escritor, e o escritor moçambicano não é um escritor, é um escritor moçambicano” funciona como um alerta para a necessidade de "Moçambique produzir literatura" e não se contentar com literatura "pseudoafirmativa” ou "nacionalista” (COELHO, 2012, p. 144). O apelo por uma literatura para lá dos enquadramentos e/ou constrangimentos nacionais e nacionalistas não significa propor uma literatura autotélica sem relação alguma com o contexto histórico, político e/ou social; trata-se, isso sim, de explorar a tensão produtiva entre estória e história (cf. VECCHI, 2009, pp. 241-243), ética e estética (cf. COELHO, 2012, p. 142), texto e contexto:

Eu acho que o campo da literatura é um campo próprio, onde exista realidade social não reflectida directamente, mas refractada na qualidade da cidadania. Quer dizer, o escritor é cidadão. Agora, eu não estou de acordo em transformar 
a literatura, por exemplo, num instrumento de denúncia ou num instrumento de justiça social, isso extravasa. (COELHO, 2012, p. 135)

A questão que se coloca não é se há relação entre literatura e sentido e referencialidade, mas que tipo de relação existe: "There is no literature without a suspended relation to meaning and reference. Suspended means suspense, but also dependence, condition, conditionality. In its suspended condition, literature can only exceed itself" (DERRIDA; ATTRIDGE, 1992, p. 48). ${ }^{2}$ Não sendo nunca apenas um documento ou um instrumento (de "denúncia”, de "justiça social”), a literatura é sempre mais do que apenas literatura ("cidadania" ou outras). Por outras palavras, a literatura política pode atuar politicamente, enquanto (ao ser, por ser) literatura (cf. RANCIÈRE, 2010).

\section{POR QUEM DE DIREITO E DIANTE DA LEI. A FOLHA DE PAPEL TIMBRADO E A CARTA BRANCA}

Como em tantos escritos de Franz Kafka, a lei ocupa um papel de destaque em "Casas de ferro". O comentário de Michael Hofmann relativamente à stasis nos escritos de Kafka (Hoffman faz referência a um "Kafka-time") servirá, além do mais, como ponto de partida, no caso específico de "Casas de Ferro", para considerar as questões do espaço (o pilar da geografia) e do tempo (o pilar da história) que norteiam Índicos indícios com a relação da estória com o espaço (os que "ali vivem" COELHO, 2005, p. 47 - estão sempre a mais nos espaço que ocupam) e com o tempo (os que "ali vivem", sempre atrasados em relação às forças que visam despejá-los). É sobretudo na questão temporal que o recurso aos escritos de Kafka pode ser iluminante. Segundo Michael Hofmann, nos escritos de Kafka, "[t]here are three paradigmatic moments, though they make up a sort of trinity, not interchangeable but certainly co-substantial". 3 Em Kafka, "it is almost always too late" (Gregor Samsa acorda já transformado, o prisioneiro de "Colónia Penal” foi já sentenciado), e não há reversão possível dos processos em marcha; concomitantemente,

2 "Não existe literatura sem uma relação em suspenso com o significado e a referência. Em suspenso significa suspense, mas também dependência, condição, condicionalidade. Na sua condição em suspenso, a literatura apenas pode exceder-se a si própria."

3 "[...] existem três momentos paradigmáticos, que constituem uma espécie de trindade, não permutável mas certamente cossubstancial”. 
"the end has not yet happened", por muito escassa que seja a esperança; por fim, "then there is perhaps the truest or most illusory moment, the middle moment, the Zeno moment, the infinite possibility of infinitisemal change" (HOFMANN, 2007, pp. xi-xii). "Casas de ferro" tem início com um processo irremediavelmente já em marcha e termina em suspensão (com uma frase iniciada pelo advérbio "talvez" e com o verbo no presente do subjuntivo), sem que o desfecho chegue a acontecer (é constantemente adiado com as deslocações dos residentes de lugar para lugar e, no final da estória, a deslocação do lugar dos residentes), não deixando também de trazer à tona uma "infinite possibility of infinitisemal change", com o final em aberto no qual as casas de ferro, aparentemente, e ao contrário do que uma voz refere no texto, ainda "são capazes de largar" (COELHO, 2005, p. 71).

No entanto, não é só no sentido de "inatividade" ou "suspensão" que a noção de stasis poderá ser iluminadora. Também no significado de stasis enquanto guerra civil, que Giorgio Agamben (2015) desenvolveu como paradigma político. A relação "conflituosa”, para recuperar as palavras de Borges Coelho, entre África e o mar (e, mais especificamente, entre Moçambique e o mar Índico), não éalheia à tensão eviolência (simbólica e/ ou material) entre os abandonados projetos coloniais e as novas ordens na pós-colónia, entre quem apropria e quem é espoliado, entre quem produz ordens com preâmbulos e quem não sabe ler. Na estória, o mar (e o areal, e os barcos, metonimicamente associados ao mar) frustra, colocando em suspensão a progressão da nova ordem, dos poderes obscuros e das forças mais ou menos ilegítimas que, com contornos orwellianos, e em nome do "Desenvolvimento", procuram ir "arrumando convenientemente o passado e organizando o presente para se ir de encontro ao futuro" (COELHO, 2005, p. 52).

O início de "Casas de ferro" apresenta uma força policial, a Força Municipal, buscando uma autoridade local que possa intimar, em nome das "Autoridades", para que os ocupantes do abandonado hotel Grande Hotel da Beira, desocupado já no período colonial - deixem as imediações. A Força empunha "uma folha de papel timbrado, carimbada e assinada por quem de direito, ordenando, depois de um necessário preâmbulo, o despejo" (COELHO, 2005, p. 48), papel que apenas a muito

4 “[...] é quase sempre tarde demais"; "o fim não aconteceu ainda"; "existe então aquele que é talvez o momento mais verdadeiro ou mais ilusório, o momento do meio, o momento Zenão, a possibilidade infinita de ínfima mudança”. 
custo encontra um leitor competente de entre o grupo de iletrados e semiletrados ocupantes/residentes. A missiva invoca interesses comuns e o bem comum para enquadrar a ordem de despejo. Confrontadas com a rendição da Força Municipal, as Autoridades consultam os Empresários, e estes últimos, com recurso à maquinaria de demolição, acabam por forçar a evacuação do "povo", como se lhe refere o texto. O heterogéneo grupo que aí vivia harmoniosamente refugiar-se-á de forma espontânea e algo dispersa em três barcos velhos e enferrujados, encalhados no areal. Os ocupantes acabam por prosperar modestamente com o comércio que fazem no areal, quando há maré baixa, e montam um bazar, o que desencadeia uma nova investida (métodos e discursos semelhantes) por parte das forças e interesses que antes os haviam expulsado e que acabaram por demolir o Grande Hotel. No entanto, os planos das Autoridades são frustrados pela areia (que dificulta a movimentação da maquinaria dos Empresários) e pelo levantamento do mar, que faz vítima entre os "emigrantes" nos barcos.

Em "Casas de ferro", as autoridades usam de força para impor a (sua) lei. A lei, que é evocada amiúde, impõe-se pela lei da força àqueles que não conseguem erguer a sua voz nem em protesto (no final de contas, estariam protestando contra a lei) nem em prol de si próprios, quer enquanto indivíduos, quer enquanto coletivo. Na estória, as forças da lei (com recurso à lei da força) reapropriam os espaços e os lugares dos que neles vivem, expropriando (no sentido preciso de "esvaziar de propriedade") aqueles que o narrador ironicamente denomina de "manifestantes":

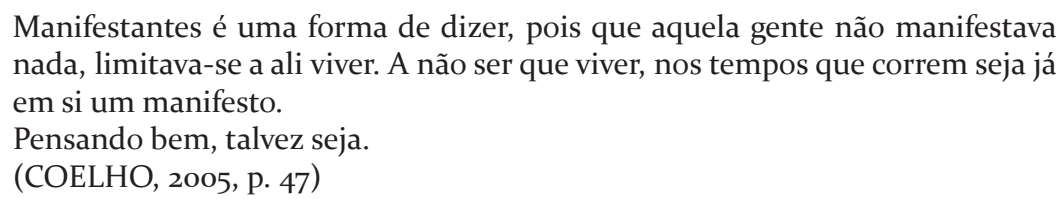

Esses "manifestantes" (que sem se poderem manifestar são já manifestantes) estão duplamente diante da lei, para evocar Kafka uma vez mais. Em primeiro lugar, uma lei é imposta, uma lei que os residentes não sabem ler nem compreender, mas que, independentemente disso, os irá perseguir. A lei é imposta pelas forças da lei (Força Municipal), por força da lei (devidamente legitimada e empossada por "quem de direito", as "Autoridades"). Quando a primeira abordagem, já de si desproporcional ("clara desproporção entre a Força e os manifestantes" - COELHO, 2005, 
p. 47) falha, porque não há, de entre o povo, uma "autoridade" que possa "tomar conhecimento", entra em palco a maquinaria pesada de demolição.

Além disso, encontram-se fisicamente diante da Lei, no seu caminho, e são projetados como obstáculo, obstruem a Lei que lhes é apresentada em folha de papel timbrado pela Força Municipal: as agressivas novas fardas da Força Municipal ("capacetes com viseiras, escudos, bastões" COELHO, 2005, p. 47) e, consequentemente, em parte substituindo-se à Força Municipal, a ameaçadora presença das máquinas de demolição, de modo a "abrir o caminho" à Lei, acabam por fundir e confundir a força (da Lei, do cumprimento da Lei) com a violência (imposição de leis à força). Tal distinção é dificultada ainda pela razão, explicitada no início da estória, que as Autoridades consultam e cedem a iniciativa aos Empresários que, de facto, dispõem (d)a lei e aparentam ser a eminência parda por detrás de "quem de direito". Desse modo, não é apenas o deferimento de um desfecho, com a fuga e perseguição, e, sobretudo, com o final, em suspenso, como acima referido, que evoca a noção de stasis. A esta dimensão (Kafkiana, segundo Hoffman) de stasis, acresce a de (agambeniana, digamos) de stasis como guerra civil: a Lei - comunicada em ambas as ocasiões nas folhas com preâmbulos verborrágicos de floreada retórica que não disfarçam a "seca, espremida" (COELHO, 2005, p. 70) ordem de despejo - é incompreensível para a quase totalidade dos destinatários e impõe-se apenas como violência simbólica e pela lei da força com a chegada dos camartelos. A violência não chega a concretizarse porque os habitantes, quando concretamente ameaçados, se escapam e, no final, o intuito das variadas Forças que os perseguem é frustrado (pela areia e pela água do mar) quando os ocupantes dos barcos encalhados não têm, aparentemente, mais por onde escapar.

A pergunta que se impõe, então, é se é possível distinguir entre a força da lei e a lei da força, entre força legítima e ilegítima, entre força justa e injusta, força violenta e não violenta. Como nota Derrida - que pensa na expressão "enforce the law" (que se traduz como "fazer cumprir a lei" ou "impor a lei"), revelando o quão imbricadas estão, em nível conceptual, "lei" ou "direito", por um lado, e, por outro, variados tipos de "força" e/ou "violência" -, ao abordar as palavras "enforceability" e a expressão "force de loi" na sua meditação sobre o fundamento místico da autoridade:

Le mot "enforceability" nous rappelle qu'il n'y a pas de droit que n'implique en lui-même, a priori, dans la structure analytique de son concept, la possibilité d'être "enforced", appliqué par la force. Il ya, certes, des lois non appliquées mais 
il n'y a pas de loi sans applicabilité, et pas d'applicabilité ou d'“enforceability" de la loi sans force, que cette force soit directe ou non, physique ou symbolique, extérieure ou intérieure, brutale ou subtilement discursive et herméneutique, coercitive ou régulatrice, etc.

$[\ldots]$

Comment distinguer entre cette force de la loi, cette "force de loi", comme on dit aussi bien en français qu'en anglais, je crois, et d'autre part la violence qu'on juge toujours injust? Quelle différence y a-t-il entre d'une part la force qui peut être juste, en tous cas jugée legitime, non seulement l'instrument au service du droit mais l'exercise et l'accomplissement même, l'essence du droit, et d'autre part la violence qu'on juge toujours injuste? Qu'est-ce qu'une force juste ou une force non-violente? (DERRIDA, 1990, pp. 924-926)5

Questões similares parecem assombrar o Comandante da Força Municipal, que associa diferentes processos legais a respetivos regimes políticos antes de bater em retirada do Grande Hotel: "A Força, em democracia, vem atrás para sublinhar a lei, nunca à frente abrindo-lhe o caminho" (COELHO, 2005, p. 52). Fica implícito que o processo que o Comandante lidera não é democrático, é desproporcional, e não isento de violência.

\section{VIOLÊNCIAS. CARTA BRANCA, FOLHA BRANCA}

Torna-se assim inevitável confrontar a violência no, e como, pano de fundo: "A violência atravessou sempre a nossa história [de Moçambique] e, mesmo quando não traz em si a explicação central, condiciona todos os outros factores" (COELHO, 2011, p. 108). Autoridade, lei, poder, política, entre outros, são apenas alguns dos fatores estruturados sob o signo da violência. Quer a violência simbólica quer a violência crua, ambas fazem parte, simultaneamente, da ideologia e do quotidiano na colónia e na

5 “A palavra 'enforceability' faz-nos lembrar que não existe direito que não implique em si mesmo, a priori, na estrutura analítica do seu conceito, a possibilidade de ser 'enforced', aplicado pela força. Existem certamente leis não aplicadas, mas não há lei sem aplicabilidade, e não existe aplicabilidade ou 'enforceability' da lei sem força, seja direta ou não, física ou simbólica, exterior ou interior, brutal ou subtilmente discursiva e hermenêutica, coerciva ou reguladora etc. [...] Como distinguir entre esta força da lei, esta 'força de lei', como, creio, se diz em francês e em inglês, e, por outro lado, a violência que julgamos ser todavia injusta? Que diferença existe entre, por um lado, a força que pode ser justa, ou em qualquer caso julgada legítima, não apenas o instrumento ao serviço do direito, mas inclusivamente o exercício e a realização do direito, a essência do direito e, por outro lado, a violência que julgamos ser todavia injusta? O que é uma força justa ou uma força não violenta?" 
pós-colónia, sem esquecer - como, aliás, argumenta Derrida em Force de loi - qualquer tipo de estado, incluindo o estado liberal democrata que, segundo Derrida, partilha da mesma estrutura do fundamento místico da Autoridade.

A demolição do Grande Hotel da Beira - que num certo sentido funciona apenas como preâmbulo e pretexto para a tentativa de sujeição e incorporação do (que é projetado como) outro ("os manifestantes") do, e pelo, ipse (Autoridade) - chama a atenção para mais uma declinação de violência, a do ipseismo, legado da razão universalista e do discurso colonialista que dela emergiu. A incessante demanda pela sublação do(s) outro(s) no e pelo próprio alimenta as Autoridades, num movimento que, mais do que simplesmente excluir, procura sujeitar os manifestantes e emigrados às leis, às ordens e ordenações, a uma visão de passado, presente e futuro. Não se trata apenas do fato de qualquer cultura ser, por prática e vocação, colonial, como avança Derrida em Le monolingualisme de l'autre (1996); ainda que, e fazendo uso de uma formulação inspirada em Orwell, todas possam ser coloniais, algumas provaram ser mais colonialistas que outras. A contribuição derridiana, segundo Achille Mbembe (2013), permite uma releitura da biografia da Europa, por dentro da tradição europeia, em consonância com a crítica pós-colonial. Tal crítica faz-se:

non plus sous le signe de la raison et de l'universel, mais à partir de la thématique du loup, c'est-à-dire du devenir-bête et du devenir-animal d'un souverain qui ne se détermine comme souverain qu'en tant qu'animal, et ne s'institue comme souverain que par la possibilité de dévorer son ennemi. (MBEMBE, 2013, pp. $74-75)^{6}$

Nesse sentido, convém relembrar que os preâmbulos abrindo caminho à ordem de despejo propriamente dita, necessários, segundo o narrador, plenos de retórica sobre a preocupação com o bem-estar das populações, com o futuro e o bem comum, servem como lembrete da seguinte afirmação de Mbembe (2013, p. 82), evocativa de Derrida, que convém ter em mente:

6 “[...] já não sob o signo da razão e do universal, mas a partir da temática do lobo, ou seja, do devir-besta e do devir-animal de um soberano que não se configura como soberano senão enquanto animal, e não se institui como soberano senão pela possibilidade de devorar o seu inimigo." 
L'on sait donc, désormais, qu'en partie la rhétorique de l'humanisme et de l'universalisme a souvent servi de paravent pour la force - une force qui ne sait pas écouter et qui ne sait pas se transformer. ${ }^{7}$

Uma força que não escuta e que não se sabe transformar é necessariamente violenta, muito possivelmente injusta, mas pode também estar dentro da legalidade, em conformidade com a lei e o direito vigente. A força pode sublinhar a lei ou abrir caminho à lei, mas tratar-se-á de uma lei fechada em si própria e no próprio, que se aplica e impõe sem levar em conta as diferenças, os desvios, a alteridade e outros aspectos incalculáveis.

O despejo escrito e comunicado na "folha de papel timbrado, carimbada e assinada por quem de direito" (COELHO, 2005, p. 48) tem necessariamente de ser imposto pela força, já que apenas a mística das Autoridades vela a sua insubstancialidade, disfarça uma crua volonté de puissance tipicada numa certa razão (pós-)/(neo)colonial:

En tant que volonté de puissance, la raison coloniale est une raison à la fois religieuse, mystique, messianique, utopique. La colonisation est inséparable des puissantes constructions imaginaires et des répresentations symboliques et religieuses à travers lesquelles la pensée occidentale a figuré l'horizon terrestre. (MBEMBE, 2013, p. 90 $)^{8}$

Achille Mbembe (200o, pp. 42-43), admitindo (parcialmente, pelo menos) estar inspirado pela posição de Derrida em Force de loi, propõe-se discutir três tipos de violência na colónia cujos efeitos se farão sentir na pós-colonialidade, inclusivamente nos regimes democráticos, úteis para analisar similares questões abordadas pela estória. Esses tipos de violência são inseparáveis e, muitas vezes, dificilmente distinguíveis. A primeira é a "violence fondatrice", que "posait et autorisait non seulement le droit de conquête, mais toutes les autres prérogatives qui découlaient de celui-ci" (MBEMBE, 200o, p. 42).9 Tinha uma função instituidora ("instituant"), por dois motivos: em primeiro lugar, "elle contribuait à créer ce sur quoi

7 "Desse modo, é sabido, desde então, que, em certa medida, a retórica do humanismo e do universalismo serviu como uma cortina de fumaça para a força - uma força que não sabe escutar e não sabe se transformar."

8 "Enquanto vontade de poder, a razão colonial é uma razão simultaneamente religiosa, mística, messiânica, utópica. A colonização é inseparável de poderosas construções imaginárias e de representações simbólicas e religiosas através das quais o pensamento ocidental figurou o horizonte terrestre."

9 "[...] violência fundadora"; "estabelecia e autorizava não somente o direito de conquista, mas também todas as demais prerrogativas que daquele decorriam”. 
elle s'exerçait"; em segundo lugar, "elle se considérait comme la seule puissance jugeante de ses lois" (p. 42). ${ }^{10} \mathrm{Na}$ estória, as Autoridades, "quem de direito”, parecem exercer essa função em relação a espaços que procuram ocupar (em nome de humanismo, progressismo, universalidade etc., mas - como se verá - com equipamentos e táticas de conflito). Seu é o direito de conquista, de fazer uso e fazer aplicar a lei em proveito próprio e/ou como testa-de-ferro a interesses materiais. A constante autolegitimação é evidente, com o foco nos textos (preâmbulos e discurso), e é explicitada pelo narrador quando, dando conta de diferentes opiniões sobre o posicionamento a ter em relação à "emigração popular" para os barcos encalhados, o narrador aponta: "Sendo razão de perguntarmos se afinal há mesmo Autoridade ou apenas normais indivíduos que a inventam para poder exercê-la" (COELHO, 2005, p. 59).

A segunda figura de violência foi acima aflorada e encontra eco nos preâmbulos, enfatizados no texto, invocando o interesse pelo bem-estar das populações, pelo bem comum, pelo desenvolvimento e prosperidade. Mesmo os Empresários, eminências pardas, não se coíbem também de usarvelhas metáforas (nacionalistas?) para tocar corações e sensibilidades:

O Desenvolvimento faz-se arrumando convenientemente o passado e organizando o presente para se ir de encontro ao futuro. Lavrar e semear para poder colher, enfatizavam [os Empresários], recorrendo à cansada metáfora que ainda assim sabiam capaz de tocar sensibilidades e corações. (COELHO, 2005, p. 52).

Este tipo de violência, segundo Mbembe (2000, p. 43), é da ordem da legitimação, e tinha a função de "fournir un langage et des modèles auto-interprétatifs à l'ordre colonial, de lui donner sens, d'en justifier la nécéssité et la mission universalisante, bref, de l'aider à produire une capacité imaginaire dont l'effet était de convertir la violence fondatrice en violence autorisante"."

A terceira forma de violência “ devait en asssurer le maintien, la multiplication et la permanence. Se situant nettemente en deçà de la guerre proprement dite, elle se répétait constamment, dans les situations

10 "[...] contribuía para a criação daquilo sobre o qual exercia poder"; "considerava-se o único poder com a legitimidade de julgar as suas leis".

11 "[...] fornecer uma linguagem e modelos autointerpretativos à ordem colonial, de lhe dar sentido, de justificar a necessidade e a missão universalizante, em suma, de ajudar a ordem colonial a produzir uma capacidade imaginária cujo efeito era o de converter a violência fundadora em violência autorizadora”. 
les plus banales et les plus ordinaires" (MBEMBE, 2000, p. 43). ${ }^{12} \mathrm{Na}$ estória, manifesta-se no continuar da perseguição conduzida depois da demolição, que vê na emigração uma falta de respeito à Autoridade e que deve ser punida por tomar a decisão não autorizada de habitar as carcaças (COELHO, 2005, p. 59) e que desembocará numa investida contra os ocupantes dos barcos. E, de forma mais banal e ordinária, na Força Municipal que, entre a incursão ao Grande Hotel e a incursão aos barcos, decide fazer o povo sentir a presença da lei nos aspectos mais banais:

\begin{abstract}
Enquanto as Autoridades fechavam os olhos, aliviadas com a solução do problema, efectuava a Força Municipal regulares incursões ao areal para que o Povo se lembrasse que não vivia desgarrado como gado sem pastor; embora um pouco mais distante, havia ainda quem por ele zelasse. Inspeccionava as bancas com faro fino e olho jurídico, querendo saber de guias de remessa, licenças e taxas, papelada de importação, impostos pagos e contabilidade em dia. E a Força, com altivez e enfado, recebia as pequenas prendas da praxe para passar por cima do problema. (COELHO, 2005, pp. 63-64)
\end{abstract}

A investida que se seguirá evidencia a forma como as Autoridades e a Força visam engolir os outros (manifestantes, emigrantes etc.), mesmo após poderem demolir e arrasar o edifício colonial abandonado (Grande Hotel). Além do mais, é sintomática do que Borges Coelho observa em relação aos eventos recentes no espaço político, social e cultural moçambicano. A criação de uma tábua rasa dá-se a par da animação de um ipse, de um espaço próprio e do próprio, de propriedade, simbolizado quer na desocupação da população residente do Grande Hotel quer no arrasamento do edifício remanescente do período colonial (mas, crucialmente, não só):

Um apagamento e, ao mesmo tempo, uma demonização do tempo colonial. Como se a independência de Moçambique fosse uma folha branca onde pudéssemos começar a escrever tudo de novo. (COELHO, 2010, p. 428)

Na estória, a ordem pós-colonial repete uma ocupação colonial, no sentido em que os espaços que as Autoridades pretendem dominar em exclusivo são considerados, por elas mesmas, como - e recorrendo a Mbembe e à sua meditação sobre ocupação colonial - "terres vacantes et sans maître" [terras desocupadas e sem dono], um territorium nullius, sem

12 "[...] devia assegurar a manutenção, a multiplicação e a permanência. Situando-se manifestamente aquém da guerra propriamente dita, repetia-se constantemente nas situações mais banais e mais ordinárias". 
dono; ocupar esses espaços não implica, teoricamente, "aucunealiénation" [alienação alguma] (MBEMBE, 2000, p. 232). Ainda que na estória seja manifestamente evidente que o Grande Hotel e os barcos têm uma história e uma memória, e que são espaços marcados por heterogeneidade, diversidade, contraste, diferença de opinião e até conflito (ironicamente, são as Autoridades e o seu discurso que estão, respetivamente, esvaziadas e vazio), os manifestantes/emigrantes são espoliados (cf. MBEMBE, 200o, p. 232) sem que as forças ocupantes lhes reconheçam nenhum direito, nem quando ocupam o espaço (Grande Hotel, os barcos), nem quando simplesmente usufruem do espaço público (no areal, onde também são perseguidos).

Essa perseguição gera mesmo alguma perplexidade da parte dos emigrados nos barcos: "Aqui não há donos, estes barcos já não são capazes de largar, pensou alguém, achando que era a inveja a razão de tudo aquilo" (COELHO, 2005, p. 71). Para as Autoridades, é indiferente haver donos ou não: não reconhecem o passado, nem o legado ou memórias do Grande Hotel ou dos barcos - nem do período colonial, nem após, nem antes. As Autoridades repetem, ainda que com marcadas diferenças, o drama da colonização, no sentido em que se lhe refere Mbembe (2013, p. 183): o "drame de la colonisation" [o drama da colonização] foi o de querer trinchar pseudoestados coloniais fechados em si próprios (ênfase em próprio) e não como "fédérations des réseaux, un espace multinational" [federações de redes, um espaço multinacional], com um constante intercâmbio de culturas fluidas que, na realidade, eram, e são. Moçambique é um país cosmopolita (no presente e no - também por causa do - passado), defende Borges Coelho (2009, p. 162), e as nações consolidam-se não pelo "fechamento", mas por "intercâmbio e abertura".

A obsessão das Autoridades, na estória, em demolir e expulsar em nome de um encontro com o (projetado, legitimado) futuro, assenta-se numa similar noção de "folha branca" (muito mais do gosto dos Empresários e muito mais propícia para receitas turísticas) que Borges Coelho menciona a propósito de Moçambique. E, como tal, as Autoridades propõem-se, num processo de autolegitimação que foi anteriormente abordado, a escrever tudo de novo, repetidamente: é o que as ordens de despejo, com os preâmbulos e o despejo em si, fazem. Instituem uma nova ordem que faz tábua rasa do passado e do presente, em nome da sua visão de futuro. 
Na estória, o processo de assegurar uma "folha branca" é desencadeado por meio da "folha de papel timbrado, carimbada e assinada por quem de direito, ordenando, depois de um necessário preâmbulo, o despejo" empunhada pela Força Municipal. Procura-se a "folha branca" usando o texto, jargão incompreensível, mas - no limite - éa "carta branca” conferida aos Empresários, cuja ausência de texto contrasta com a verborreia preambular da ordem em folha de papel timbrado, que concretiza a ocupação:
E, impressionadas com a argumentação, as Autoridades, que tanto texto preambular haviam proporcionado a quem não sabia ler, proporcionaram agora a estes, formados nas melhores universidades, carta branca, sem texto algum.
Os Empresários leram aquele não-texto como lhes convinha. (COELHO, 2005, p. 53)

A carta branca revelará quer a violência que, no limite, subjaz à legitimação mística da Autoridade no discurso da carta, quer a "volonté de puissance" [vontade de poder] da razão colonial. Como relembra Mbembe (2000, p. 232), a ocupação colonial (e, poder-se-ia e dever-se-ia acrescentar, neocolonial e, porventura, pós-colonial) faz-se sob o signo (e com o vício) da "violência e da espoliação". É o "não-texto" (essa ausência que contrasta com o excesso de texto para quem não sabe ler) que permite aos empresários sobreporem-se e substituírem-se à ordem que vem na folha através da ameaça de destruição exemplificada com "a sólida parede de betão" que ergueram apenas para ser destruída pelo equipamento adequado que os empresários importaram: um camartelo "gigantesco e ameaçador" (COELHO, 2005, p. 53), também classificado como "monstro" (p. 6o). São as máquinas dos Empresários que abrem caminho à lei, nomeadamente à lei do mais forte pela lei da força com a carta branca aos Empresários do Desenvolvimento, quando, como refere o narrador, tanto texto preambular fora dado a quem não sabia ler. O problema, sugeriram os Empresários na sua discussão com as Autoridades, é não arrumar (com) o passado - se bem que não deixem de ser pragmáticos, como antes mencionado, e utilizem cansadas metáforas do passado. O risco não é o de ignorar o passado, mas o de ignorar o "seu devir": é a "tragédia de um país ignorando o seu devir" (p. 52), assim são avisadas as Autoridades pelos Empresários.

O fato de a ordem de despejo não encontrar uma Autoridade Local que possa "tomar conhecimento", perceber a linguagem e os longos 
preâmbulos, demonstra, em primeiro lugar, que a função legitimadora da violência falha não só porque não há lei para abrir caminho à Força (representada pela Força Municipal, que se identifica com a Autoridade [COELHO, 2005, p. 71]). A inseparabilidade da legitimação e da violência (fundadora) é exposta, e os residentes não têm possibilidade de distinguir, se é que é possível distinguir, entre a força da lei e a violência. Em segundo lugar, indestrinçavelmente, deslinda de forma gritante a falta de correspondência entre, por um lado, os discursos da lei e da Autoridade e, por outro, aqueles que estão sujeitados à lei enquanto instrumento de guerra assimétrica.

Tal como no caso histórico da colónia, é um confronto (neste caso, de aplicação da lei com recurso à força simbólica e à ameaça de uso da força) em que apenas um dos lados do confronto tem armas: as fardas, as folhas com os textos, os camartelos; mas sobretudo a lei, que a Autoridade maneja, exercendo o seu poder à força e pela força ao impor um discurso de autolegitimação indistinguível da violência fundadora. Emigrados para os barcos encalhados, os "manifestantes" continuam a ser "manifestantes" simplesmente porque, como parece desconfiar o narrador no início da estória, "ali vivem”. Ao serem perseguidos mesmo quando já não podem questionar ou escapar à força da lei e às forças da lei - já saíram do Grande Hotel, já cumpriram as ordens; fisicamente, não podem recuar mais, já que ocupam apenas carcaças de barcos encalhadas no areal -, torna-se evidente que quem os persegue é a lei da força e a lei do mais forte.

Comprovando a dificuldade, sobretudo do ponto de vista dos "manifestantes", em distinguir força legítima de força violenta ou entre força de lei e lei da força, a descrição das forças policiais e dos seus equipamentos e táticas, bem como a maquinaria legitimada pela carta branca/não-texto, inscrevem as forças da e ao serviço da lei como agentes de guerra. Estes evocam assim não apenas a stasis, no sentido que Agamben lhe empresta (guerra no seio da comunidade), mas também o paradigma de guerra de baixa intensidade utilizado por Mbembe (2013, p. 91) para descrever a dominação colonial. Será oportuno relembrar que a legitimação e reiteração da Autoridade não se circunscreve aos atos de violência fundacional e autorizante, e se repete constantemente em situações banais e ordinárias (MBEMBE, 2000, p. 43). A lei é usada pelas autoridades como instrumento de conflito, sob todos os preâmbulos e metáforas de Autoridades e Empresários. A lei é não só imposta apenas com recurso à Força e à violência (textos, camartelos etc.); tal como 
é evocada e utilizada pelas diferentes forças de autoridade e poderes instituídos, não se apoia na força de lei, mas sim na lei da força.

\section{AS MARCAS NA FOLHA BRANCA. NÃO-TEXTO, COM TEXTO, CONTEXTO}

No final da estória, as Autoridades e os Empresários, com todos os seus agentes, dispositivos e aparatos, encontram-se - ainda que, temporariamente, em suspenso - derrotados por areia e por água. Os camartelos (aparatos que substituem as forças da lei, enviados dos poderes a que as Autoridades servem) se afundam na areia e se tornam tão inúteis quanto (julga-se) os barcos encalhados e enferrujados que não podem largar, e mostram os limites de um sistema que, procurando "arrumar o passado, organizar o presente para ir de encontro ao futuro", revela-se impreparado para visões alternativas, para um porvir que não o "Futuro" (COELHO, 2005, p. 71) ordenado "por quem de direito" e para o qual a Força (Municipal) e a força (simbólica e material) abrem caminho. No final da estória, contudo, é a impossibilidade de encontrar "caminho seco" (p. 72) que expõe a debilidade de uma força que, relembrando Mbembe, não sabe escutar nem se sabe transformar; uma força que se autolegitima com recurso ao texto (preâmbulos, despejo) e que se aplica com recurso ao "não-texto" ("carta branca"). No entanto, esse contexto novo, em que a areia e a água do mar minam a força, demonstra quão débil é essa lei sem o poder da Força que lhe abre caminho:

Custava-lhes ver o camartelo cruzando a areia da maré vazia para vir também ali fazer o seu trabalho. Era demasiado pesado para aquela areia fofa, demasiado lento e demorado para poder chegar e partir sem que as ondas da maré cheia se atravessassem no seu caminho. (COELHO, 2005, p. 71)

A frustração da Autoridade e da Força pela água e pela areia conduz a uma situação paradoxal, do género que Derrida identifica em "Force of law", "où la plus grande force et la plus grande faiblesse s'échangent étrangement" (DERRIDA, 1990, p. 928).13

O mar é um dispositivo que expõe a fluidez das culturas, do que vem literal e metaforicamente de fora; do porvir, que não pode ser calculado,

13 “[...] em que a maior força e a maior debilidade curiosamente trocam de lugar". 
programado, antecipado, aquilo de que não se pode ir ao encontro nem para o qual basta abrir caminho.

O mar Índico nãoé menos violento, como o prova a destruição do barco Maria Luísa, e o narrador chega a descrevê-lo como um líquido camartelo (COELHO, 2005, p. 66). Na estória, o Índico pode ser entendido como uma violência que se opõe à força se, em termos sorelianos, entender-se força como o intuito de impor uma ordem social em que uma minoria governa e é automaticamente obedecida, e entender-se violência como tendendo à destruição dessa mesma ordem e ao minar da sua autoridade (cf. MBEMBE, 2016, p. 34). As Autoridades são, como nos informa o texto, quem de direito, mas direito, como relembra Derrida, não é justiça. Justiça deve ser e ter uma força que escute os outros, que se possa transformar, responder quer a textos gerais, quer a contextos específicos, que possa calcular com o incalculável:

Le droit n'est pas la justice. Le droit est l'élement du calcul, et il est juste qu'il y ait du droit, mais la justice est incalculable, elle exige qu'on calcule avec de l'incalculable; et les expériences aporétiques sont des expériences aussi improbables que nécéssaires de la justice, c'est-à-dire de moments où la décision entre le juste et l'injuste n'est jamais assurée par une règle. (DERRIDA, 1990, p. 946) ${ }^{14}$

O mar Îndico - com as suas águas revoltas pela tempestade, o areal que invade - apresenta uma incalculabilidade, expõe um contexto em que é impossível simplesmente aplicar a lei. As águas que fecham o caminho seco criam uma aporia (etimologicamente: passagem difícil/ sem passagem). $\mathrm{O}$ areal, os barcos, o mar: espaços sem fronteiras definidas, fluidos, com um grau de incalculabilidade, são "les bords du politique" [as margens do político] (cf. RANCIÈRE, 2007), funcionam enquanto teatro (de guerra e encenação), enquanto local de infiltração e contaminação face ao ataque das Autoridades que empunham a lei e a ordem ("seca, espremida"), e a Força que a vigia e aplica, quando em "terra firme” (COELHO, 2005, p. 72), e abre caminho à lei desde que tenha "caminho seco" (p. 72). A estória termina em stasis; quer como suspensão, quer como guerra civil:

14 “O direito não é a justiça. O direito é o elemento de cálculo, e é justo que o direito exista, mas a justiça é incalculável, a justiça exige que se façam cálculos com o incalculável; e as experiências aporéticas da justiça, ou seja, momentos em que a decisão entre o justo e o injusto jamais é assegurada por uma regra, são experiências tão improváveis quanto necessárias." 


\begin{abstract}
Nesse dia o tempo voltou a mudar. Chegou outra tempestade, menos violenta do que a anterior, é certo, mas em compensação mais demorada. Há já dias que o vento deambula resmungando, e que as águas, agora cinzentas, se recusam a abrir um caminho seco por onde a Força possa ali chegar. Em terra firme, sob as casuarinas, o Comandante aguarda uma oportunidade. Dentro dos barcos, é difícil saber o que aguardará o Povo.

Talvez que o Asiswa? se decida a largar, seguido na sua esteira pelo hirsuto Chamuare. (COELHO, 2005, p. 72)
\end{abstract}

Compreende-se assim que o "ali viver" - como o narrador de "Casas de ferro” aponta ironicamente no início da estória - seja uma manifestação. A estória termina sem que a Força, impedida pelas águas, "possa ali chegar" (COELHO, 2005, p. 72). A Força permanece irremediavelmente em terra firme, e a força da lei não se consegue impor aos refugiados nos barcos. Os "manifestantes", sem armas para o conflito que lhes abrem, sem poderem participar na discussão ("[p]assando directamente aos actos sem primeiro conversar?” [p. 53]), não conseguem opor-se à força da lei; contudo, o mar funciona como a interrupção da consensual lógica e lei da terra (a língua inglesa exibe o termo legal "law of the land" [lei da terra]), de semear e de colher, para usar a metáfora gasta dos Empresários: de arrumar o passado (heterogéneo, diverso, o produto de conflitos e guerras) para ir de encontro ao futuro. Em termos simbólicos, aquilo a que se poderia chamar a "law of the land" (a lei das Autoridades com jurisdição sobre o espaço, dos Empresários que visam destruir e reconstruir, fazendo uso de metáforas como "semear a terra" e "colher"), com as suas secas ordens de despejo, é interrompido pelo mar. Essa interrupção abre espaço ao "político", funcionando o final da estória como um comentário irónico à retórica cinicamente utilizada pelos Empresários, sobre semear e colher. Com um final aberto, em conflito e suspensão, "Casas de ferro" não seria consistente se propusesse os barcos como espaços fechados, utópicos e/ou heterotópicos, de uma comunidade e do bem comum. O final em aberto da estória gera ambiguidade, visto que o aventado largar dos barcos do areal para o mar entra em aberta contradição com a anterior descrição do degradado estado das embarcações e com o trágico destino da embarcação mais frágil de entre as três. Os barcos são casas sem dono, vulneráveis às forças da água (ciclicamente transformam-se em ilhas; podem também ser destruídos, como o Maria Luísa), são um espaço de contato, predicado nas marés e aberturas.

$\mathrm{O}$ mar (com as suas águas, com o areal que banha) interrompe a sublimação daqueles projetados como outros ("manifestantes") por, enum, 
ipse (Autoridades, Força), desse modo funcionando como proteção contra o ipseismo do outro e do próprio. A estória, e a literatura - com as referências às folhas brancas, é legítimo considerar uma alegoria de leitura -, fornece assim uma espécie de resposta aos estudos de filosofia política dedicados à comunidade (comunitarismo etc.), os quais, apesar das melhores intenções críticas e ideológicas, se limitam, em grande parte dos casos, a reproduzir o ipse que se procura colocar como questão (cf. ESPOSITO, 2010, p. 2). Como argumenta Roberto Esposito, "[ $\mathrm{t}]$ he community remains doubly tied to the semantics of proprium" [a comunidade permanece duplamente vinculada à semântica do proprium] (p. 2; cf. também: ESPOSITO, 2009, pp. 15-16). A violenta interrupção, no final da história, com a exposição aos limites que a invasão do mar causa, leva a que se criem as condições de uma communitas no sentido que lhe empresta Esposito, em que ser sujeito não é estar sujeitado (a um passado arrumado, a um presente organizado ao encontro do futuro). Na visão de Esposito (2010) em Communitas 7, a que não está alheia uma certa (re)leitura do mar enquanto figura, os sujeitos não encontram um princípio de identificação ou uma redoma asséptica dentro da qual possa ser estabelecida uma comunicação transparente ou mesmo um conteúdo a ser comunicado. Os sujeitos são-no apenas enquanto "subjects of their own proper lack, of the lack of the proper" [sujeitos da sua própria falta, da falta do próprio] (p. 7), ao passo que a comunidade:

The community isn't a mode of being, much less a "making" of the individual subject. It isn't the subject's expansion or multiplication but its exposure to what interrupts the closing and turns it inside out: a dizziness, a syncope, a spasm in the continuity of the subject. (ESPOSITO, 2010, p. 7) ${ }^{15}$

O areal, tal como o mar, desafia a "law of the land" como espaço-limite e como limite do espaço, funcionando simultaneamente como menos e mais do que um espaço político, ou o lugar do outro; mais que um espaço, é um limite e uma operação, um espaçamento (cf. DERRIDA, 1972, pp. 107108 e 130) que produz alteridade e no qual o próprio (passado, presente, futuro) não se fecha sobre si mesmo - antes se expõe, como acima referido, aos seus limites ("como se procurassem chegar à água funda para ali em

15 "A comunidade não é um modo de ser, muito menos uma construção do sujeito individual. Não é a expansão ou a multiplicação do sujeito, mas antes a sua exposição ao que interrompe o fechamento e o vira do avesso: uma vertigem, uma síncope, um espasmo na continuidade do sujeito." 
grupo se afogarem" [COELHO, 2005, pp. 54-55]). O areal, ciclicamente e - no final da estória - por tempo indeterminado invadido pelo mar, é uma folha branca em que se destacarão os elementos que possibilitarão, pela frustração dos intentos da Força e das Autoridades, novas visões políticas e a emergência de uma comunidade que não é a abstração "Povo" referida pelas autoridades, que é constituída por "sujeitos" (no sentido oposto ao de "sujeitados" à lei), "de fora do Povo, mais do mundo do concreto" (p. 54):

O que é certo é que no dia que se seguiu aos ameaçadores preliminares do camartelo, e antes que este passasse às vias de facto, arremetendo contra o Grande Hotel, houve meia dúzia de famílias que pegaram nas suas coisas e abandonaram o velho edifício, caminhando com elas à cabeça em direcção à praia. Entrando nela, prosseguiram pelo extenso areal como se procurassem chegar à água funda para ali em grupo se afogarem. Seguiram-nos com a vista os restantes moradores, a partir das varandas do Grande Hotel, à sombra das frondosas árvores que cresciam nelas. Seguiram-nos com a vista até que a distância os foi engolindo, pequeninos pontos escuros, caganitas de pássaro em imensa folha branca, que era essa a cor do areal.

Afloram nessa folha branca, meio enterrados nela, grandes barcos que parecem ter sido espalhados ao acaso por Deus ele próprio, no tempo em que era criança e ali gostava de brincar. (COELHO, 2005, pp. 54-55)

Os "pequeninos pontos escuros" são uma marca que contrasta, na "folha branca" do areal, com o excesso de texto da folha de papel timbradoe com o não-texto da carta branca aos Empresários. As marcas dos moradores e dos barcos ilustram nessa folha branca as marcas de uma singularidade que não pode ser englobada por uma ordem, projeto, ou programa, ao passo que a metáfora das caganitas de pássaro e a imagem de Deus em criança ridicularizam a mística de autolegitimação das Autoridades. As caganitas e os brinquedos espalhados são a marca da imprevisibilidade, do acidental e da imaginação. A folha branca, ao contrário da carta branca, apresenta marcas e um (con)texto que mina o não-texto de Empresários e Autoridades. As marcas são o texto que frustra a leitura (de não-textos) como "lhes convinha".

"Casas de ferro", enquanto texto literário, com o confronto entre residentes e Autoridade/Força desde a expulsão do Grande Hotel até ao momento em que o mar Índico reclama as embarcações encalhadas que lhe serviam de último refúgio, está longe de ter apenas função documental (histórica, política, geográfica, até literária); tem, antes de mais, uma função performativa. Não se trata de uma abdicação da história (um dos pilares dos contos, juntamente com a geografia, como antes referido); 
pelo contrário, trata-se de encarar a performatividade poético-literária das estórias, um termo em tensão com o termo homófono histórias, em que a literatura funciona não como complemento ou ilustração, mas antes como um suplemento, uma revisão e visão alternativa da História e de histórias. Será oportuno relembrar que a literatura tem como função, entre outras coisas, e segundo Borges Coelho, propor "visões alternativas" e possibilidades outras, equeo "espaço deliberdadeda escrita" é "inegociável" (COELHO, 2010, p. 430). A literatura não tem necessariamente deveres (embora não signifique, como acima mencionado, descomprometimento social), mas possibilita o exercício de um direito de revisões críticas e propostas alternativas na história ("todos os aspectos do real acontecido") pelas estórias. A citação de Borges Coelho, abaixo, vem precisamente no seguimento da supracitada discussão sobre o "esquecimento do passado" e "apagamento da memória”:

O que eu quero dizer é que é preciso olhar - criticamente e sem preconceitos para todos os aspectos do real acontecido, e isto é um direito que eu reivindico, um direito que a literatura, num certo sentido, possibilita. A literatura tem a possibilidade de quebrar com as visões viciadas, e de propor novas leituras e olhares. (COELHO, 2010, p. 430)

Visões viciadas... tanto na história (vício da espoliação e violência) como em literatura (pseudoafirmativa) e nacionalista. O final da estória imbrica o leitor e o leva a investir na imaginação de um futuro que não aquele concebido e concebível no presente (da história e da estória). Um futuro estoriado que não repita o drama histórico da colonização, "de vouloir fixer des frontières rigides à ce qui était, structurellement, un espace de circulation et de marchandage, flexible, à géométrie variable" (MBEMBE, 2013, p. 183). ${ }^{16}$ Um futuro cuja possibilidade a literatura permite e possibilita, um futuro a que é da mais elementar justiça poder ter direito; um futuro que se possa imaginar, que se possa transformar, que seja mais do que a aplicação de um programa semeado no presente (arrumando o passado, organizando o presente), que não seja imposto forçosamente, com o caminho até ao futuro já presente e idealizado (com receitas, desenvolvimento etc.), aberto à força e pela força, pela lei do mais forte apenas. A performatividade do texto é, aporeticamente - e a aporia é significativa -, ao mesmo tempo condição e produto de uma imaginação

16 "[...] de querer impor fronteiras rígidas ao que era, estruturalmente, um espaço de circulação e de trocas, flexível, de geometria variável”. 
do futuro, sem letras maiúsculas (como na estória) e nunca totalmente previsível ou calculável. Imaginar o futuro passa também por imaginar o direito a um futuro outro, para lá do direito e de "quem de direito":

Mas, nós não podemos abdicar de uma imaginação do futuro, eu não digo de uma concepção do futuro, porque a concepção traz uma ordem, e a ordem é sempre castrante e põe a questão do poder; mas a imaginação, nós não podemos ceder nesse campo, porque se não imaginarmos o futuro, não podemos ter uma ética também, e não podemos ter uma estética. (COELHO, 2012, p. 142)

A escrita das margens do Índico, em Índicos indícios, promove essa "abertura ao desconhecido" (geográfica, histórica, literária) e, na sua imaginação do futuro, conjuga a promessa de uma visão alternativa com o "real acontecido", dissimulado, mas em cena: a literatura "shows nothing without dissimulating what it shows and that it shows it" (DERRIDA; ATTRIDGE, 1992, p. 48). ${ }^{17}$ O final em aberto e em suspenso da estória transmite, como se viu, apenas uma (kafkiana) ínfima esperança: a frase final inicia-se com um "talvez..." e apresenta os tempos verbais no subjuntivo. Mas uma ínfima esperança é por vezes apenas o suficiente para imaginar politicamente o futuro para lá da força de lei e/ou da lei da força.

\title{
AUTHORITIES, FORCES AND VIOLENCES IN "CASAS DE FERRO” ("IRON HOUSES”), BY JOÃO PAULO BORGES COELHO: BETWEEN THE OPENING TO THE UNKNOWN AND THE IMAGINATION OF THE FUTURE
}

\begin{abstract}
João Paulo Borges Coelho’s short story (estória, to be more precise) “Casas de ferro" [Iron Houses], and namely its approach to the indexes of the Indian Ocean, provides an apt starting point for a reflection on matters of law, authority, force and violence. The short story acts as a literary supplement to historical, geographical, political, and philosophical visions; the sea, as a literary and textual device, bursts at the end of the short story as an element of conflict and suspension, prompting an open ending and staging an opening to the unknown. This allows for a reworking of the relations between self and other beyond the mere framing of the other as other to the self; between others that the selves (Authority, Force) seek to appropriate and plunder (inhabitantes and refuges) in the name of a law and a discourse which overflows from colonialism (as well as neocolonialism and post-coloniality) as it appeals to the common good and pretends to have the best interests of the population and the "development" of the country in mind. The Indian Ocean, as a topos and a trope, does more than simply configure another espace/place (under utopian and/or heterotopic guise) or another "Future" which may offset what is
\end{abstract}

17 “[...] não mostra nada sem dissimular o que mostra e que o mostra”. 
taking place on dry ground, already projected by the Authority and the respective Force. The sea (and the elements associated with it, such as the boats and the sand) functions as a device which activates literature's role and duty to approach the "real that took place" while simultaneously "imagining the future" and offering alternative visions to the dominant one.

Keywords: Indian Ocean; Achille Mbembe; Jacques Derrida.

\section{REFERENCIAS}

AGAMBEN, Giorgio. La guerra civile come paradigma politico. Turim: Bolatti Boringhieri, 2015.

BHABHA, Homir. DissemiNation: Time, Narrative, and the Margins of the Modern Nation. In: BHABHA, Homir (Org.). Nation and Narration. Londres: Routledge, 1990, pp. 291-322.

BRUGIONI, Elena. Contiguidades ambíguas. Críticas pós-coloniais e literaturas africanas. In: LEITE, Ana Mafalda; KHAN, Sheila; FALCONI, Jessica; KRAKOWSKA, Kamila (Orgs.). Nação e narrativa pós-colonial I. Angola e Moçambique - Ensaios. Lisboa: Edições Colibri, 2012, pp. 379-392.

COELHO, João Paulo Borges. Índicos indícios I: Setentrião. Lisboa: Caminho, 2005.

COELHO, João Paulo Borges. [Entrevista a Rita Chaves]. Via Atlântica, n. 16, 2009, pp. 151-166.

COELHO, João Paulo Borges. [Entrevista a Elena Brugioni]. A literatura e o léxico da póscolonialidade: uma conversa com João Paulo Borges Coelho. Diacrítica, v. 3, n. 24, 2010, pp. 427-44.

COELHO, João Paulo Borges. [Entrevista a Ana Patrício Vicente Peixinho Santos]. Navegações, v. 4, n. 1, 2011, pp. 107-109.

COELHO, João Paulo Borges. [Entrevista]. In: LEITE, Ana Mafalda et al. (Orgs.). Nação e narrativa pós-colonial II. Angola e Moçambique - Entrevistas. Lisboa: Edições Colibri, 2012, pp. 131-144.

DERRIDA, Jacques. Positions. [Entrevista a Jean-Louis Houdebine et Guy Scarpetta]. In: Positions. Paris: Éditions de Minuit, 1972, pp. 51-133.

DERRIDA, Jacques. Force of Law. The "Mystical Foundation of Authority" / Force de Loi. Le "fondement mystique de l'Autorité". Trad. Mary Quaintance. Cardozo Law Review, v. 11, 1990, pp. 920-1.045.

DERRIDA, Jacques. Le monolingualisme de l’autre. Paris: Galilée, 1996. 
DERRIDA, Jacques; ATTRIDGE, Derek. This Strange Institution Called Literature. An interview with Jacques Derrida. In: ATTRIDGE, Derek (Org.). Acts of Literature. Trad. Geoffrey Bennington e Rachel Bowlby. Londres: Routledge, 1992, pp. 33-75.

ESPOSITO, Roberto. Comunidad, inmunidad y biopolítica. Trad. Alicia García Ruiz. Barcelona: Herder, 2009.

ESPOSITO, Roberto. Communitas. The Origin and Destiny of Community. Trad. Timothy Campbell. Stanford, CA: Stanford University Press, 2010.

HOFMANN, Michael. Introduction. In: KAFKA, Franz. Metamorphosis and Other Stories. London: Penguin, 2007, pp. vii-Xv.

HOFMEYR, Isabel. The Complicating Sea. The Indian Ocean as Method. Comparative Studies of South Asia, Africa and the Middle East, v. 32, n. 3, 2012, pp. 584-59o.

MBEMBE, Achille. De la postcolonie. Essai sur l'imagination politique dans l'Afrique contemporaine. 2. ed. Paris: Karthala, 2000.

MBEMBE, Achille. Sortir de la grande nuit. Essai sur l'Afrique décolonisée. Paris: Éditions La Découverte, 2013.

MBEMBE, Achille. Politiques de l'inimité. Paris: Éditions La Découverte, 2016.

PEARSON, Michael N. Port cities and intruders. The Swahili Coast, India, and Portugal in the Early Modern Era. Baltimore: Johns Hopkins University Press, 1998.

RANCIÈRE, Jacques. On the Shores of Politics. Londres: Verso, 2007.

RANCIÈRE, Jacques. The Emancipated Spectator. Trad. Gregory Elliott. Londres: Verso, 2009 .

RANCIÈRE, Jacques. The Politics of Literature. In: Dissensus. On Politics and Aesthetics. Londres: Bloomsbury, 2010, pp. 152-168.

VECCHI, Roberto. Excepting the Exception. A Bloodstained Cartography of Mozambique in João Paulo Borges Coelho's Índicos indícios. In: DEMARIA, Cristina; DALY, Macdonald. The Genres of Post-Conflict Testimonies. Nottingham: Critical, Cultural and Communications Press, 2009, pp. 237-247. 